\title{
POWER QUALITY MEASUREMENTS IN TWO NORWEGIAN MV NETWORKS WITH DISTRIBUTED GENERATION
}

\author{
Anngjerd PLEYM, Helge SELJESETH \\ SINTEF Energy Research - Norway \\ Anngjerd.Pleym@sintef.no
}

\begin{abstract}
Power Quality measurements have been performed in two Norwegian MV networks which both have a limited amount of distributed generation connected. The measurements indicate that the generation units do not cause power quality problems. The results are however not directly transferable to networks with higher share of distributed generation.
\end{abstract}

\section{INTRODUCTION}

The amount of distributed generation is steadily increasing in the electricity networks. However, these networks in their present form are not designed for accommodation of large amounts of such generation, and there has been some concern in the network companies regarding the interaction with the network, especially related to power quality. In this context it has been of interest to investigate the power quality level in networks with distributed generation through measurements.

This report considers such power quality measurements in two different Norwegian MV networks that both have got a limited amount of small-scale generation connected.

It is also of interest to compare the results from this specific measurement campaign with general results from former PQ measurements in Norwegian MV networks.

\section{MEASUREMENT SITES}

Measurement site no 1, network with hydro power plant The first measurement site is in a rural $22 \mathrm{kV}$ network with five feeders. The network is fed from a strong $132 \mathrm{kV}$ network. A small-scale hydro power plant is connected to one of the five feeders. The connection point is close to the feeding point of the $22 \mathrm{kV}$ network. The generator is a synchronous generator, and the generator voltage is $660 \mathrm{~V}$. The generator is connected to the network through a dedicated transformer.

The maximum load on the network is approximately 7.5 MW, and the small-scale hydro power plant has an installed capacity of $900 \mathrm{~kW}$. The load is mostly residential and agricultural load, but one of the feeders has a large share of industrial load. A sketch of the network is shown in Figure 1.

\section{Measurement site no 2, network with wind farm}

The second measurement site is also a rural $22 \mathrm{kV}$ network with five feeders. The network is fed from a $66 \mathrm{kV}$ network. A wind farm consisting of 5 wind generators is connected at the end of one of the five $22 \mathrm{kV}$ feeders, at a distance of
$28 \mathrm{~km}$ from the feeding point of the $22 \mathrm{kV}$ network. This feeder mainly consists of overhead line (FeAl 1x25).

All the generators in the wind farm are directly connected asynchronous machines running at $690 \mathrm{~V}$. The three $400 \mathrm{~kW}$ wind generators are connected to the $22 \mathrm{kV}$ network through a common 22/0.69 kV transformer. The two $500 \mathrm{~kW}$ wind generators are connected to the $22 \mathrm{kV}$ network through one 22/0.69 kV transformer each.

72 distribution transformers are connected to the same $22 \mathrm{kV}$ feeder as the wind farm. The load consists mainly of residential and public service load. A sketch of the network to which the wind farm is connected is shown in Figure 2.

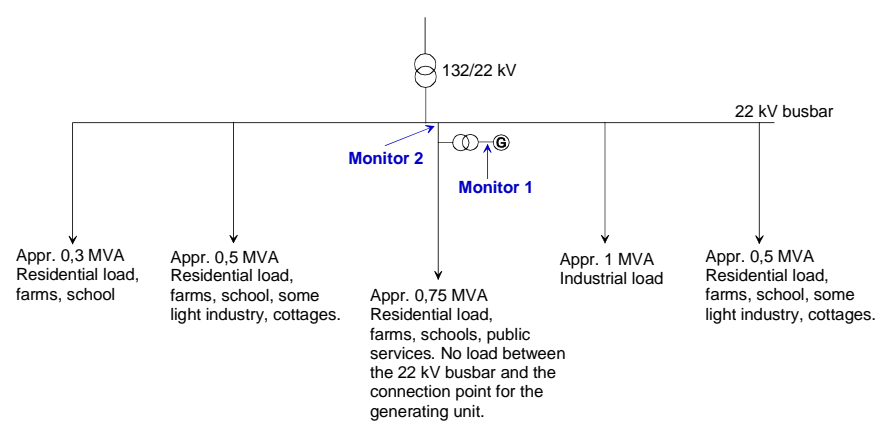

Figure 1 Sketch of the $22 \mathrm{kV}$ network with a small scale hydro power plant connected

\section{MEASUREMENT CAMPAIGN}

In both of the monitored networks measurements were performed at the generator site and at the origin of the feeder to which the generator is connected. (22 kV busbar in substation.)

The measurements are performed to get an overview of the power quality in networks with distributed generation. The measurement periods were 4 and 3 months on the two sites respectively. The relatively long measurement periods were used to get an as good as possible picture of randomly occurring disturbances.

\section{MEASUREMENT EQUIPMENT}

\section{Measurement site no 1}

The measurements were performed by using advanced power quality monitors. For the measurements in the network with the hydro power plant two BMI PQ Nodes were used, one of type 8010 and one of type 8020 . These monitors are able to register triggered data and data with regular time intervals 
simultaneously.

The maximum allowable input voltage for the instruments is $600 \mathrm{~V}$, and consequently the measurements at both the generator site and in the substation had to be performed using transformers. In both locations existing measurement transformers in the installation are used. At the generator site the transformer ratio was 690/110, and in the substation the ratio was 22000/110. The currents are also measured using existing current transformers in the installations. The current transformer rations were 1000/5 and 200/5 for the generator site and the substation respectively. Both currents and voltages are scaled using processing software in such a way that presented results reflect the real currents and voltages at the sites.

The data from both instruments were downloaded using floppy disks due to lack of telephone connection. No synchronization of the clocks has been performed during the measurement period. Earlier experience has shown that the deviation in the clocks over time might be substantial for these instruments. A direct comparison between disturbances in the substation and at the generator based on time of occurrence of the events might therefore be difficult.

\section{Measurement site no 2.}

The BMI PQ Nodes are not able to record voltage fluctuations (flicker) which is a relevant parameter for wind generators, so for the measurements in the network with the wind farm, one Unilyzer 902 and one QWave were used. The measurements at the wind generator were performed using the Unilyzer 902, and the measurements in the substation were performed by use of the QWave. This is indicated in Figure 2.

At both sites the voltage measurements are performed on the secondary side of existing measurement transformers. At the generator site the currents are measured by means of Rogowski coils adjusted to the input limits of the instrument. At the transformer station the currents are measured on the secondary side of current transformers.

The measurements data from the Unilyzer 902 instrument were downloaded via a direct connection to a PC at the spot and then analysed with the software accompanying the instrument (Unipwer PQ Online and Unipower Power Profile). The downloading was done by utility personnel 5 times during the measurement period, resulting in 5 data files. The measurement data from the QWave were kept in the instrument memory and downloaded directly to an office PC at the end of the measurement period. Analyses of the data were performed by use of the software QBrowser, accompanying the instrument.

\section{MEASUREMENT RESULTS}

In both of the monitored networks some power quality events occurred, but no serious problems were found in

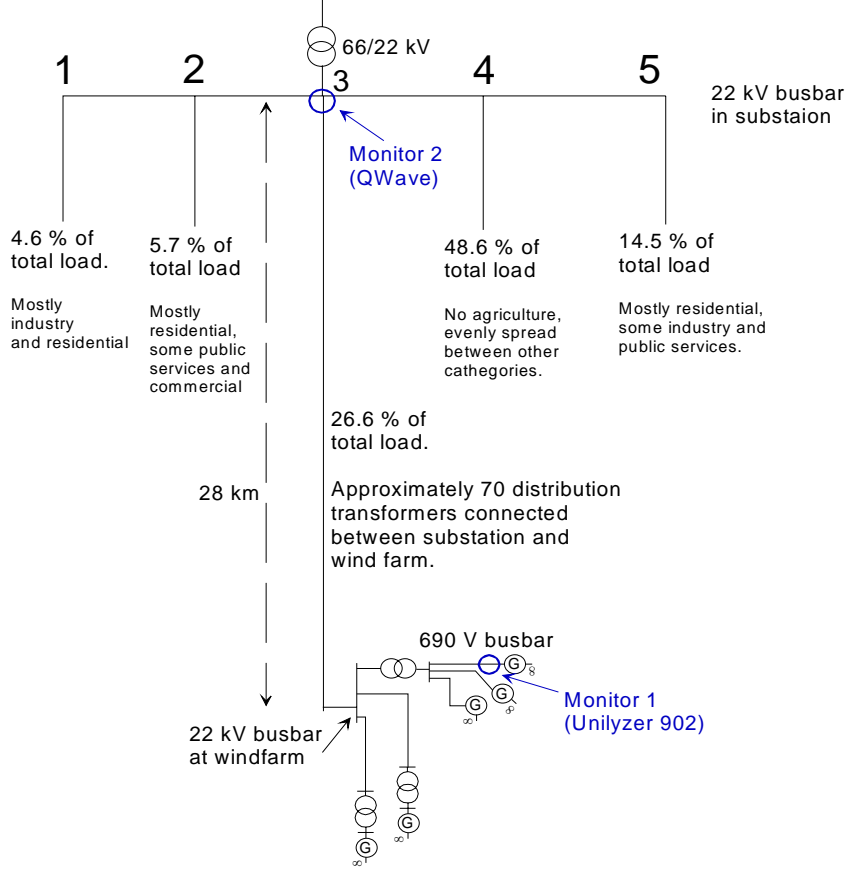

Figure 2 Sketch of the $22 \mathrm{kV}$ network with the wind farm connected network.

either network A summary of the measurement campaign is given in Table 3 .

\section{Detailed results from measurement site no 1}

The 21 voltage dips recorded at the hydro power generator are mostly small and of short duration. A summary of the dips in a UNIPEDE table is given in Table 1.

Table 1 Registered voltage dips at the hydro powe generator (trigger phase)

\begin{tabular}{|c|c|c|c|c|c|c|}
\hline \multirow[b]{2}{*}{ Depth } & \multicolumn{6}{|c|}{ Duration [seconds] } \\
\hline & $0,001-0,1$ & $0,1-0,5$ & $0,5-1,0$ & $1,0-3,0$ & $3,0-20,0$ & $20,0-60,0$ \\
\hline $10-15 \%$ & 7 & & 3) & & & \\
\hline $15-30 \%$ & 3 & & 5 & & & \\
\hline $30-60 \%$ & & & 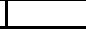 & & & \\
\hline $60-99 \%$ & & & & & & \\
\hline
\end{tabular}

At the substation a total of 71 voltage dips are registered. These are summarised in Table 2.

Table 2 Registered voltage dips at the substation (trigger phase)

\begin{tabular}{|c|r|r|l|l|l|l|}
\hline \multirow{2}{*}{ Depth } & \multicolumn{7}{|c|}{ Duration [seconds] } \\
\cline { 2 - 7 } & $0,001-0,1$ & $0,1-0,5$ & $0,5-1,0$ & $1,0-3,0$ & $3,0-20,0$ & $20,0-60,0$ \\
\hline $10-15 \%$ & 14 & 7 & & & & \\
\hline $15-30 \%$ & 5 & 16 & & & & \\
\hline $30-60 \%$ & & 30 & & & & \\
\hline $60-99 \%$ & & & & & & \\
\hline
\end{tabular}

A visualisation of the voltage dips in magnitude duration plots are given in Figure 3 and Figure 4.

The RMS voltage trends show that the voltage has been relatively stable over the measurement period, both at the generator site and at the substation. The variation is, as expected, larger at the generator site than at the substation. Histograms showing the variation in RMS voltage for the two locations are given in Figure 5 and Figure 6. 
Table 3 Summary of the measurements performed.

\begin{tabular}{|c|c|c|c|c|}
\hline & $\begin{array}{l}\text { At the hydro } \\
\text { power generator }\end{array}$ & $\begin{array}{l}\text { At the appurtenant } \\
\text { transformer station }\end{array}$ & $\begin{array}{l}\text { At the wind power } \\
\text { generator }\end{array}$ & $\begin{array}{l}\text { At the appurtenant } \\
\text { transformer station }\end{array}$ \\
\hline Number of days in the measurement period & 114 & 114 & 85 & 85 \\
\hline Number of days with disturbances & 15 & 38 & 0 & 6 \\
\hline Number of voltage dips recorded & 21 & 72 & 0 & 18 \\
\hline Number of wave faults recorded ${ }^{1)}$ & 72 & 240 & - & - \\
\hline Number of outages recorded & $1^{2)}$ & 2 & 0 & - \\
\hline Number of impulses recorded & 1 & 22 & 0 & - \\
\hline Max voltage THD & 1.8 & 2.1 & 5.1 & 3.7 \\
\hline Min voltage THD & 0.76 & 0.45 & 0.7 & 0.57 \\
\hline Max Pst & - & - & 1.6 & 6.63 \\
\hline Min Pst & - & - & 0.05 & 0.08 \\
\hline Max Plt & - & - & 0.8 & 3.57 \\
\hline Min Plt & - & - & 0.12 & 0.11 \\
\hline
\end{tabular}

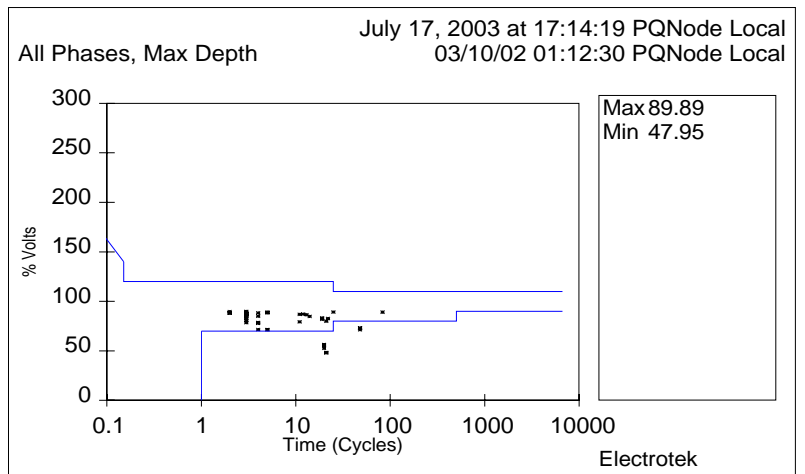

Figure 3 Magnitude duration plot for voltage dips registered at the hydro power generator

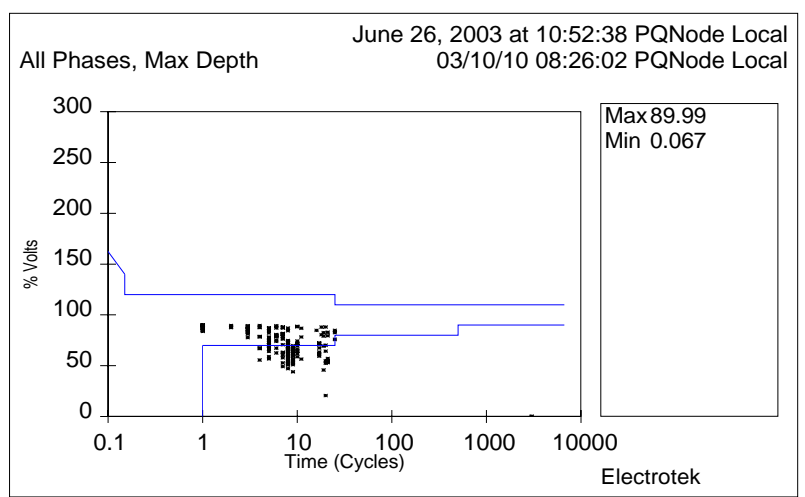

Figure 4 Magnitude duration plot for voltage dips registered at the substation

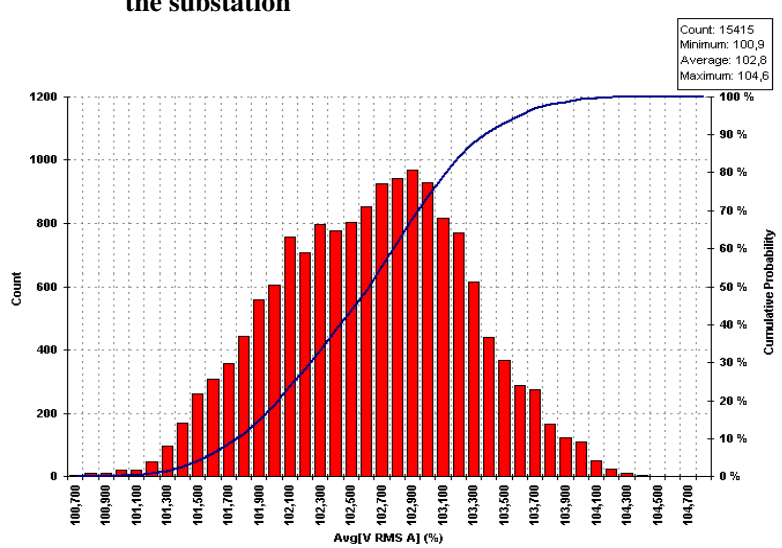

Figure 5 Histogram showing the variation in RMS voltage at the hydro power generator site.

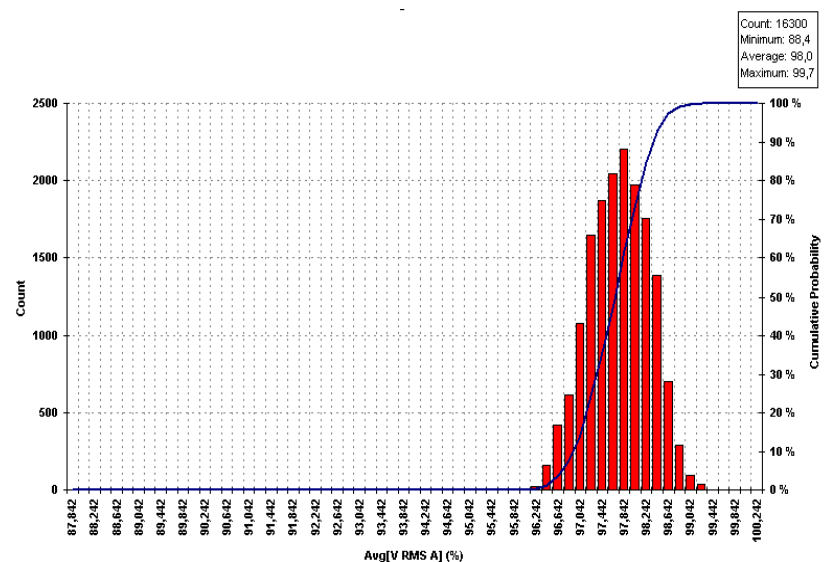

Figure 6 Histogram showing the variation in RMS voltage at the substation

The variation in RMS current is relatively large due to variations in load in the network and production from the hydro power generator. These are natural variations and the histograms are not included since the value of the information is limited.

The dominating voltage harmonic components registered in the network are the $5^{\text {th }}$ and $7^{\text {th }}$. The THD is around 1.0 with the larger value at the generator site and the smaller value at the substation. This is as expected. The registered THD values do not indicate any problems with harmonics in the network. This is in accordance with experience in the network company. Histograms showing the variation in voltage THD for the two locations are given in Figure 7 and Figure 8.

A few transient overvoltages are registered in the substation, but these overvoltages are small and with limited energy.

\section{Detailed results from measurement site no 2}

No voltage dips are registered at the wind power plant. Whether this is due to instrument errors or a real lack of events at the site is not clear. A few voltage dips are registered in the feeding substation. A summary of the dips in one of the phases (L2) is shown in Table 4. No magnitudeduration plot is available for these data. 


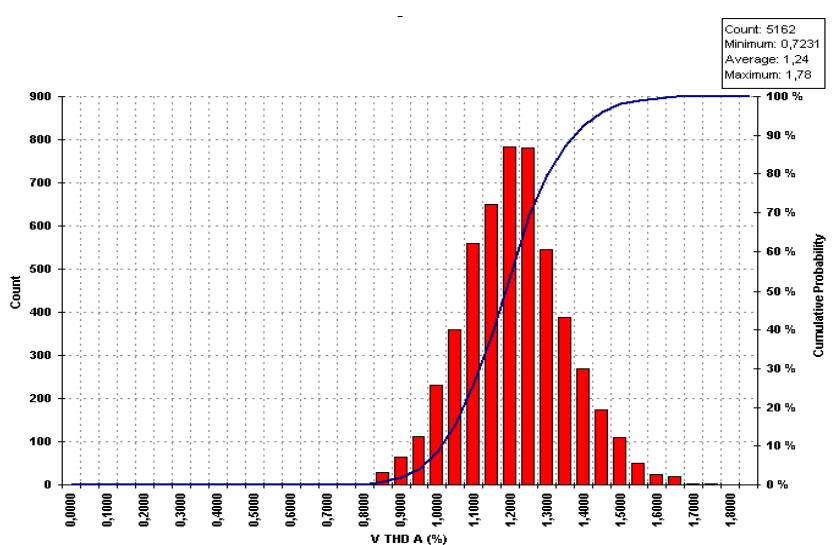

Figure 7 Variation in voltage THD at the hydro power generator site

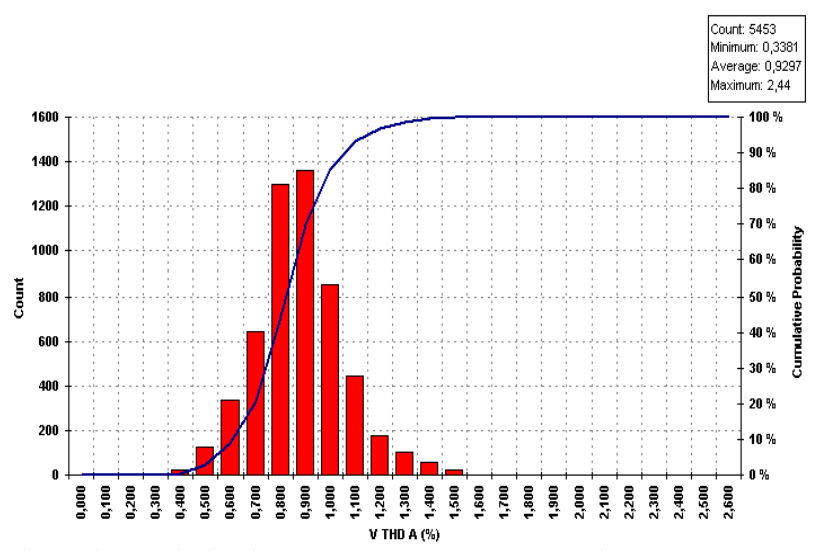

Figure 8 Variation in voltage THD at the substation

Table 4 Registered voltage dips in phase $L 2$ in the substation

\begin{tabular}{|l|r|r|l|l|l|l|}
\hline \multirow{2}{*}{ Depth } & \multicolumn{5}{|c|}{ Duration [seconds] } \\
\hline & $0,001-0,1$ & $0,1-0,5$ & $0,5-1,0$ & $1,0-3,0$ & $3,0-20,0$ & $20,0-60,0$ \\
\hline $10-15 \%$ & 1 & 7 & & & & \\
\hline $15-30 \%$ & 2 & 1 & & & & \\
\hline $30-60 \%$ & 1 & & & & & \\
\hline $60-99 \%$ & & & & & & \\
\hline
\end{tabular}

The voltage in the substation has been stable through the measurement period. A trend curve showing this voltage is given in Figure 9. The RMS voltage at the wind generator site varies somewhat more. This is not unexpected since the wind farm is situated at the end of a long radial feeder and that the voltage will vary with varying production by the wind generators. Due to limitations in the processing software for these measurements, it is not possible to have an RMS trend curve for the whole measurement period. A trend curve showing the RMS voltage at the wind generator site for a period of 13 days is shown in Figure 10.

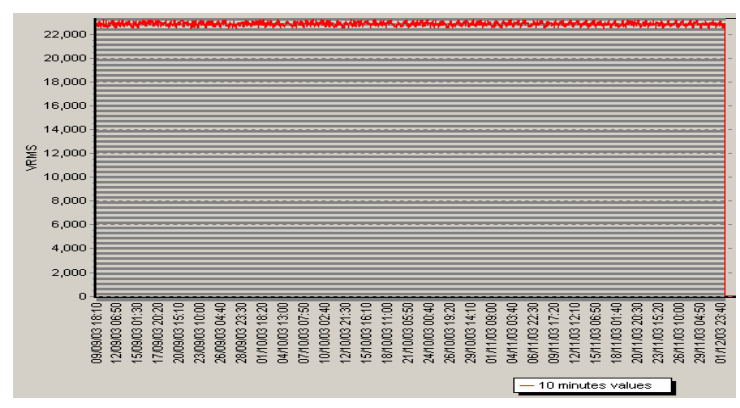

Figure 9 RMS voltage trend for the substation (wind power) Figure 10 RMS voltage trend for the wind generator site for a period of

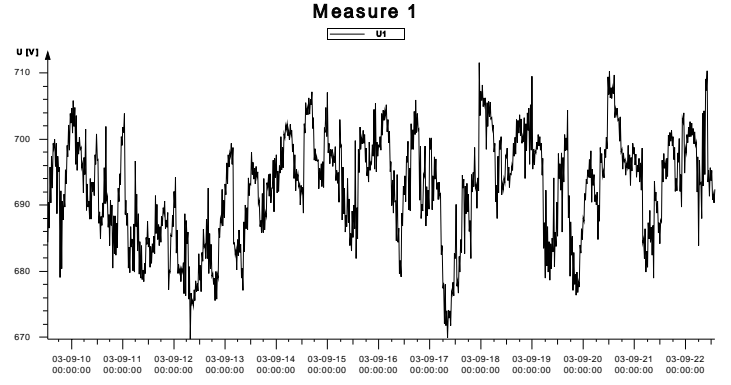

13 days

Again the RMS currents will vary according to load and production variations.

The harmonic content in the voltage is moderate in both locations, but is substantially higher and more varying at the wind generator site than in the substation. The voltage THD at the wind generator site is in the area 1.5 to $4 \%$ while the voltage THD in the substation lies between 0.75 and $1.35 \%$. A trend curve for the voltage THD at the wind generator site for a period of 13 days is shown in Figure 11, and a trend curve for the voltage THD in the substation for the whole measurement period is shown in Figure 12.

Figure 11 VoltageTHD trend for the wind generator site for a period of

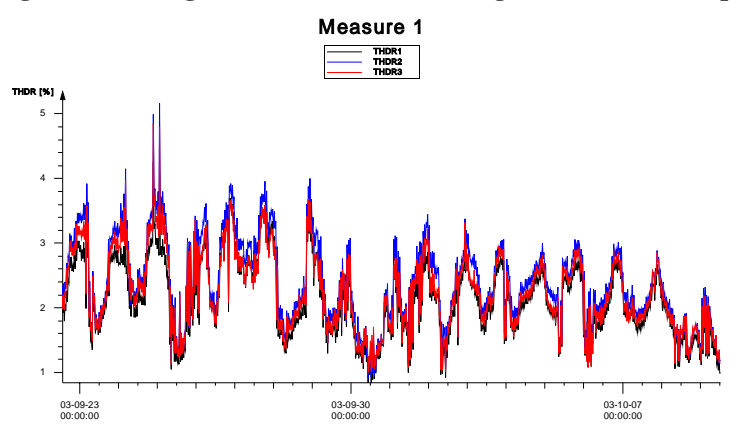

13 days

The dominating harmonic components in this network is the $5^{\text {th }}$ and the $7^{\text {th }}$.

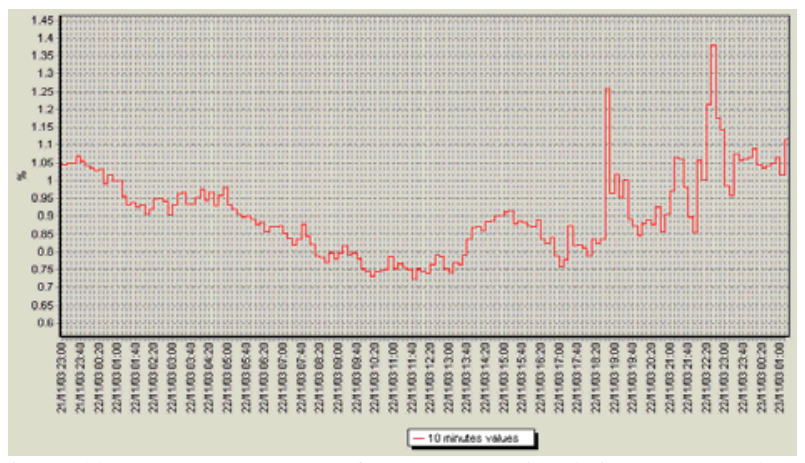

Figure 12 Voltage THD trend for the substation (wind generator)

For networks with wind generation connected flicker might be a problem. The flicker level in terms of Pst (short term flicker) and Plt (long term flicker) is measured. At the wind generator site the levels are acceptable with the majority of the Pst values in the area $0.2-0.4$, but with some peaks

\section{CIRED2005}


exceeding 1.0. The Plt values at the wind generator site are in the same are, but the peaks do not exceed 1.0. A trend curve showing the Plt values at the wind generator site can be found in Figure 13.

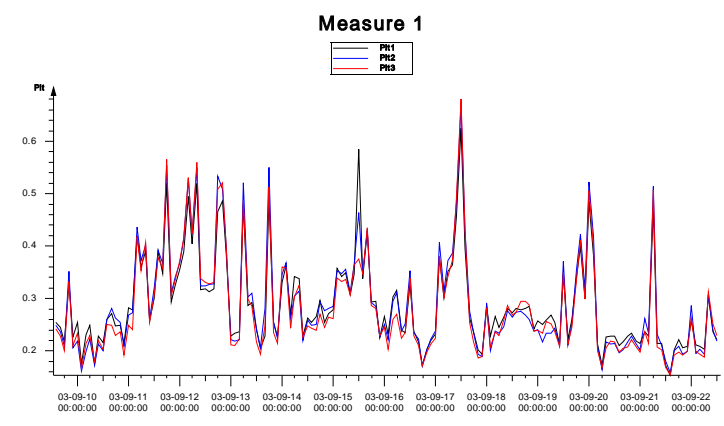

Figure 13 Plt values for the wind generator site for a period of 13 days

At the substation the Pst values are generally below 0.5, but with some very high peaks. These peaks can also be found in the long term values, Plt. An analysis of the data shows that the peak values in Pst and Plt is coincident with voltaged dips in the network, and that the values thus are special cases and not really a high flicker level. A trend curve showing the Plt values for the substation is given in Figure 14.

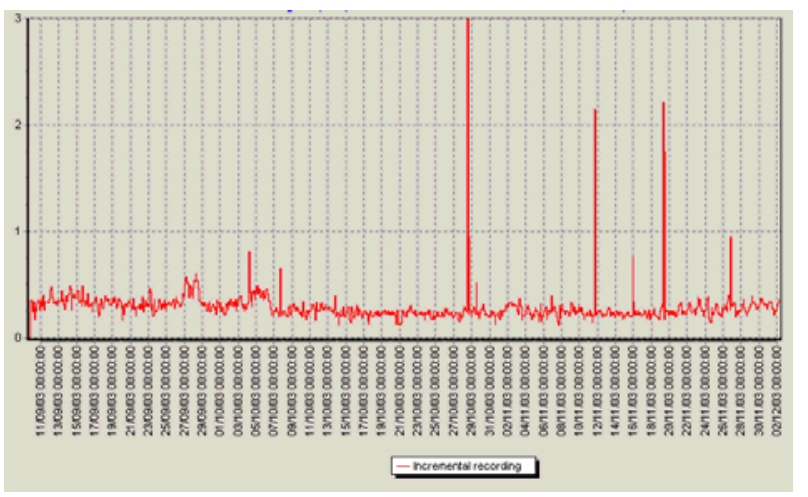

Figure 14 Plt values for the substation (wind generator)

\section{COMPARISON WITH GENERAL PQ DATA}

Since 1992 Norwegian network companies have performed power quality measurements in their networks. The measurement results are gathered in a national database. A comparison between the data measured in the two networks with distributed generation and the average values from the database [ref] is performed.

The average number of voltage dips per low voltage measurement point per year is 71. If the number of voltage dips at the hydro power generator site is extrapolated to a year, the number of dips is 67 which is below the average number. In the $\mathrm{MV}$ voltage network $(1 \mathrm{kV}-35 \mathrm{kV})$ the average number of voltage dips is 55 per measurement point per year. An extrapolation of the data from the first substation gives a yearly number of dips equal to 227 which is very high. A lot of these dips are due to wave shape faults that are large enough to influence the RMS value of the voltage. These voltage dips are not found at the generator site. An extrapolation of the data from the second substation gives a yearly number of dips equal to 77 which is also a high number.

The average THD found in Norwegian low voltage networks is approximately $1.5 \%$ in low voltage networks and $1.0 \%$ in MV networks. This in good agreement with the measured results in the two investigated networks.

The $50 \%$ value for flicker measured in low voltage networks is 0.39 for Pst and 0.35 for Plt. This is also in good agreement with the results found in this investigation. There were no available flicker statistics for the MV network in the database.

\section{CONCLUSIONS}

Measurements are performed in two different MV networks in Norway, both having a limited amount of distributed generation connected. The measurement periods have a length of 4 and 3 months respectively.

Some power quality events are registered in both networks, but the registrations do not indicate that the disturbances are due to the distributed generation units. This conclusion is in accordance with the experiences made in the two networks.

The measured disturbances are in relatively good agreement with general power quality data from Norwegian networks.

It is necessary to note that the amount of distributed generation in both the MV networks is limited. The conclusions with respect to power quality drawn on the basis of the measurements performed, can thus not uncritically be transferred to networks with higher share of distributed generation.

\section{ACKNOWLEDGEMENTS}

The measurements that form the basis for this paper is performed in the EU project DGFACTS.

The authors wish to thank Kvikne Rennebu Kraftlag and Nord-Trøndelag Elektrisitetsverk for letting us use their network and for their kind co-operation during the measurement periods.

\section{REFERENCES}

1. "Database of quality of supply measurements on selected DG sites”, D5 from the DGFACTS project. (http://dgfacts.labein.es/dgfacts/index.jsp)

2. H. Seljeseth: "Voltage quality and short interruptions in Norway. Status for the period 19932003)”

Trondheim, Norway: SINTEF Energy Research, 2004 (In Norwegian) 